\title{
RESEARCH
}

Open Access

\section{Clinical evaluation of neuroinflammation in child-onset focal epilepsy: a translocator protein PET study}

Kuriko Kagitani-Shimono ${ }^{1,2,3^{*}}$ (D), Hiroki Kato ${ }^{4}$, Ryoko Kuwayama ${ }^{2,3}$, Koji Tominaga ${ }^{1,2,3}$, Shin Nabatame ${ }^{2,3}$, Haruhiko Kishima ${ }^{3,5}$, Jun Hatazawa ${ }^{4,6}$ and Masako Taniike ${ }^{1,2}$

\begin{abstract}
Background: Neuroinflammation is associated with various chronic neurological diseases, including epilepsy; however, neuroimaging approaches for visualizing neuroinflammation have not been used in the clinical routine yet. In this study, we used the translocator protein positron emission tomography (PET) with $\left[{ }^{11} \mathrm{C}\right]$ DPA713 to investigate neuroinflammation in the epileptogenic zone in patients with child-onset focal epilepsy.

Methods: Patients with intractable focal epilepsy were recruited at the Epilepsy Center of Osaka University; those who were taking any immunosuppressants or steroids were excluded. PET images were acquired for 60 min after intravenous administration of $\left[{ }^{11} \mathrm{C}\right]$ DPA713. The PET image of $\left[{ }^{11} \mathrm{C}\right]$ DPA713 was co-registered to individual's magnetic resonance imaging (MRI), and the standardized uptake value ratio (SUVr) in regions of interest, which were created in non-lesions and lesions, was calculated using the cerebellum as a pseudo-reference region. In the case of epilepsy surgery, the correlation between SUVr in lesions and pathological findings was analyzed.

Results: Twenty-seven patients (mean age: $11.3 \pm 6.2$ years, male/female: 17/10) were included in this study. Of these, $85.1 \%$ showed increased uptake of $\left[{ }^{11} \mathrm{C}\right]$ DPA713 in the focal epileptic lesion. Three patients showed epileptic spasms, suggesting partial seizure onset, and all 18 patients with abnormal lesions on MRI were similarly highlighted by significant uptake of $\left[{ }^{11} \mathrm{C}\right]$ DPA713. DPA713-positive patients had a broad range of etiologies, including focal cortical dysplasia, tumors, infarction, and hippocampal sclerosis. Five out of nine MRI-negative patients showed abnormal $\left[{ }^{11} \mathrm{C}\right]$ DPA713 uptake. The SUVr of $\left[{ }^{11} \mathrm{C}\right]$ DPA713 in lesions was significantly higher than that in non-lesions. In seven patients who underwent epilepsy surgery, increased $\left[{ }^{11} \mathrm{C}\right]$ DPA713 uptake was associated with microglial activation.

Conclusions: This study indicates that $\left[{ }^{11} \mathrm{C}\right]$ DPA713 uptake has valuable sensitivity in the identification of epileptic foci in child-onset focal epilepsy, and inflammation is implicated in the pathophysiology in the epileptic foci caused by various etiologies. Further research is required to establish diagnostic tools for identifying focal epileptogenic zones.
\end{abstract}

Keywords: Epilepsy, Neuroinflammation, Microglia, Positron emission tomography, TSPO

\footnotetext{
* Correspondence: kuriko@ped.med.osaka-u.ac.jp

'Department of Child Development, United Graduate School of Child Development, Osaka University, Suita, Osaka, Japan

${ }^{2}$ Department of Pediatrics, Osaka University Graduate School of Medicine, Suita, Japan

Full list of author information is available at the end of the article
}

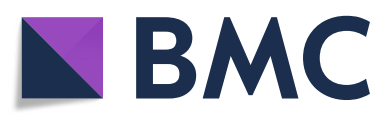

(- The Author(s). 2021 Open Access This article is licensed under a Creative Commons Attribution 4.0 International License, which permits use, sharing, adaptation, distribution and reproduction in any medium or format, as long as you give appropriate credit to the original author(s) and the source, provide a link to the Creative Commons licence, and indicate if changes were made. The images or other third party material in this article are included in the article's Creative Commons licence, unless indicated otherwise in a credit line to the material. If material is not included in the article's Creative Commons licence and your intended use is not permitted by statutory regulation or exceeds the permitted use, you will need to obtain permission directly from the copyright holder. To view a copy of this licence, visit http://creativecommons.org/licenses/by/4.0/ The Creative Commons Public Domain Dedication waiver (http://creativecommons.org/publicdomain/zero/1.0/) applies to the data made available in this article, unless otherwise stated in a credit line to the data. 


\section{Background}

Epilepsy, a common chronic neurological disease, affects approximately 65 million people worldwide [1] and is the third contributor to the global burden in neurological disorders [2]. Etiologies, such as genetic structural abnormality, infection, metabolic abnormality, and autoimmune encephalitis [3], have been recognized, while the common pathophysiological mechanisms include (1) increased excitatory neurotransmission and/or reduced inhibitory neurotransmission at the epileptogenic zone and (2) recurrent seizures that may lead to further epileptogenesis or progression of epilepsy. Therefore, the first-line choice for epilepsy is antiepileptic drugs that modify the imbalance between excitatory and inhibitory neurotransmission or suppress ictogenesis. In the last two decades, many new antiepileptic drugs have been developed; however, approximately $30 \%$ of patients still have refractory prognosis [4].

Accumulating evidence indicates that the inflammatory process is a strong trigger and modulator in the epileptic brain. For instance, kainic acid-induced seizure mice (a model of temporal epilepsy) showed activated microglia shortly after acute seizures [5] [6], and human tissues from the resected foci of refractory epilepsy exhibited reactive microglia [7-9]. Rasmussen's encephalitis and other encephalitis-associated epilepsies are well known as inflammation-associated epilepsies [10]. Accordingly, some anti-inflammatory agents, such as corticosteroids, immunoglobulins, and immunosuppressants, are the most effective therapies for epileptic encephalopathies [11]. Because neuroinflammation plays an important role in epilepsy and other neurodegenerative disorders, specific in vivo markers for neuroinflammation are needed for therapeutic purposes.

Positron emission tomography (PET) imaging using translocator protein (TSPO)-binding radioligands is the most widely used method to assess microglial activation in patients. TSPO, an 18-kDa translocator protein, which is located on outer mitochondrial membranes, has been demonstrated to be a peripheral benzodiazepine receptor [12] and has been consistently observed in activated microglia [13]. In the past two decades, because of a high requirement for the detection of neuroinflammation in vivo, numerous TSPO PET ligands have been developed, and they were classified into the first- and second-generation ligands. ${ }^{11} \mathrm{C}$ PK11195 is the most widely used first-generation ligand but has some disadvantages, such as high non-specific binding and low brain bioavailability [14]. Several second-generation ligands, such as ${ }^{11} \mathrm{C}$-PBR28, ${ }^{11} \mathrm{C}-\mathrm{DPA} 713,{ }^{18} \mathrm{~F}-\mathrm{PBR} 111$, and ${ }^{18}$ F-DPA714, have been developed to improve the signal to noise ratio, although low-affinity is still a problem in participants with rs6971 polymorphism (Ala147Thr) in the TSPO gene [15].
Neuroinflammatory pathophysiology has been investigated using those TSPO ligands in human neurological conditions. For instance, both the acute dysmyelinating lesion and secondary progressive white matter lesion in multiple sclerosis showed higher TSPO radioligand uptake [16-18], and ${ }^{11} \mathrm{C}$-DPA713 uptake was more sensitive to and showed better correlations with microglial activation at the acute and chronic phases after stroke [19]. Moreover, high TSPO distribution was associated with post-treatment Lyme disease syndrome [20] and clinical stage and extent of tau aggregation in patients with Alzheimer's disease [21], and patients with traumatic brain injury, especially repeated injuries, showed higher TSPO radioligand uptakes in the atrophic brain regions compared to the controls [22]. These findings further support the usefulness of TSPO PET in the detection of neuroinflammation in neurological disorders.

Notably, many studies using TSPO PET were performed in adult patients, except for one study where age-related changes in TSPO distribution were examined in only ten children with normal TSPO distribution [23]. Therefore, it remains unclear whether there are differences in TSPO distribution between child and adult epilepsy, and few studies have investigated the usefulness of TSPO PET in child-onset epilepsies, including epileptic encephalopathies. Therefore, this study aimed to examine (1) the usefulness of TSPO PET in detecting the epileptogenic zone in child-onset epilepsy using $\left[{ }^{11} \mathrm{C}\right]$ DPA713; (2) the factors that influence TSPO distribution, such as age, etiology, and seizure frequency; and (3) the consistency between histological examinations of surgical specimens and TSPO uptake among various etiologies.

\section{Methods \\ Participants}

Patients with intractable focal epilepsy aged more than 1 year were recruited at the epilepsy center of Osaka University Hospital between December 2016 and March 2019. Patients who were taking any immunosuppressants or steroids or were at risk of becoming pregnant were excluded from the study. In all patients, except one, who had controlled seizure, seizure types were diagnosed using video-encephalography (video-EEG) (EEG1200; Nihon-koden). Furthermore, the epileptogenic focus was identified with seizure semiology, ictal video-EEG, and magnetoencephalogram (RICOH), and confirmed by structural magnetic resonance imaging (MRI) (3T Discovery MR 750w system, GE Healthcare), and ${ }^{18}$ F-2-deoxy-2-fluoro-D-glucose PET (FDG-PET) (Eminence SOPHIA SET-3000 GCT/X, Shimadzu Co). Seven patients did not undergo FDG-PET based on the attending physician's judgment. All participants were 
checked for the TSPO binding polymorphism by genotyping of re6971 (A/A: high-affinity; A/T: mixed-affinity; and $\mathrm{T} / \mathrm{T}$ : low-affinity). Seizure frequencies were classified as yearly (one to eleven times/year), monthly (one to four times/month), weekly (two to six times/week), and daily (more than one time/day).

\section{MRI data acquisition}

We performed 3T-MRI(Discovery MR750W, GE Healthcare)with a 24-channel-head coil using the following parameters: silent T1W; TR/TE $=880 / 0.016 \mathrm{~ms}$; FOV $=$ $240 \mathrm{~mm}$; Matrix $=240 \times 240$; slice thickness, $1.0 \mathrm{~mm}$; gap, $0.5 \mathrm{~mm}$; 280 slices; acquisition time, $5 \mathrm{~m} 10 \mathrm{~s}$.

\section{PET imaging and analysis}

$\left[{ }^{11} \mathrm{C}\right]$ DPA713 was prepared using the SUMITOMO Gas-Phase Synthesizer C-GPS 100 system at the Radiopharmaceutical Laboratory of Osaka University Hospital. Mean molar activity at the end of synthesis was $141.0 \pm$ $36.6 \mathrm{GBq} / \mathrm{mmol}$ (range 53.5-192.1 GBq/mmol).

Some children who could not keep still were sedated with either pentobarbital, thiopental, pentazocine, levomepromazine, risperidone, triclofos, diazepam, midazolam, or some combination of the aforementioned sedatives (Table 2). $\left[{ }^{11} \mathrm{C}\right]$ DPA713 was administered intravenously over $30 \mathrm{~s}$ by an infusion pump as scans started, and the administration dose of the trace was around $7 \mathrm{MBq} / \mathrm{kg}$. The PET images were acquired for $60 \mathrm{~min}$ by Eminence SOPHIA SET-3000 BCT/X (Shimazu Co, Kyoto, Japan) in a three-dimensional acquisition mode. Before the emission scan, transmission data were acquired using a rotating Cs137-point source for attenuation correction. The time course (0-90 $\mathrm{min})$ of the asymmetry index $[\mathrm{AI}(\%)=200$

$\left.\times \frac{\text { ipsilateral VOI value }- \text { contralateral VOI value }}{\text { ipsilateral VOI value }+ \text { contralateral VOI value }}\right]$ was calculated in 14 patients with a unilateral abnormality on MRI (ipsilateral volume-of-interest [VOI]: VOI in the abnormal lesion seen on MRI, contralateral VOI: VOI in the contralateral normal area). It is found that AI was significantly elevated after administration and reached a plateau at approximately $60 \mathrm{~min}$ (Supplementary Figure). Therefore, the PET image frame from 40 to $60 \mathrm{~min}$, which was the final stage of the elevation phase, was used for the subsequent assessment. The late plateau phase was not chosen to increase the image accuracy because we used low-dose imaging to reduce the radiation exposure and the dosage of sedative drugs for patient safety. The static PET count images were used as standardized uptake values (SUVs), which were corrected for body weight and injected activity of each patient to make SUV images. Then, the SUV images for $\left[{ }^{11} \mathrm{C}\right]$ DPA713PET were co-registered to the individual's 3D T1-weighted MRI image using the Image Registration and Fusion Tool in the PMOD 3.6 software package (PMOD Technologies Ltd). The $\left[{ }^{11} \mathrm{C}\right]$
DPA713PET results were compared with those obtained by other neuroimaging analyses and were defined as positive or negative by a radiologist and two epileptologists.

\section{Measurement of $\left[{ }^{11} \mathrm{C}\right]$ DPA713 distribution and region of interest analysis}

We made one region of interest (ROI) $(10 \times 10 \times 10$ $\mathrm{mm}^{3}$ ) for each lobe at the bilateral frontal, temporal, parietal, and occipital cortices; hippocampus; cingulate; and cerebellum and another ROI at each focal lesion in patients with definite MRI lesions using Amide's Medical Imaging Data Examiner (AMIDE: http://amide. sourceforge.net/; Fig. 2a). After no obvious lesion was confirmed in all the cerebellums by MRI, the SUV ratio (SUVr) was calculated for an ROI/cerebellum [24]. To compare the SUVr between lesions and non-lesions, all SUVr of non-lesion ROIs and each SUVr from one lesion ROIs were averaged for each patient. Lesions were defined as (1) morphological abnormal lesion and suggesting as epileptic foci by electroencephalography (EEG) and/or MEG and (2) normal appearance lesion, observed on MRI, but suggesting as epileptic foci by EEG, MEG, and/or FDG-PET. In cases of widely affected lesions in one lobe, estimated by MRI, the ROIs in the lobe were excluded from the non-lesion ROIs.

\section{Immunohistochemistry}

Seven patients underwent focal resection according to clinical semiology, neuroimaging, video-EEG, and electrocorticogram; the lesion was confirmed to be removed by postoperative MRI. The resected brain tissues were formalin-fixed, embedded in paraffin blocks, and sectioned at $5-\mu \mathrm{m}$ thickness. After quenching with $0.03 \%$ hydrogen peroxide and blocking with normal serum, sections were incubated with primary antibodies (mouse monoclonal anti-human CD68 antibody [100 × dilutions; DAKO,] and mouse anti-glial fibrillary acidic protein (anti-GFAP) antibody [2000 × dilution; DAKO]) overnight, followed by appropriate biotinylated secondary antibodies (400 $\times$ dilutions) (Vector) and avidin/biotin staining (Vector ABC Elite Kit and DAB Kit, Vector Laboratories Inc). Brightfield images (magnification = 10) were obtained using a NanoZoomer 2.0RS virtual microscope (Hamamatsu photonics K.K). The CD68- or GFAP-positive area was calculated using Image J (https://imagej.net/Fiji/Downloads; threshold: 35-255 for CD68 and 200-255 for GFAP). To make Fig. 4d, e, contrast and brightness were adjusted with Photoshop software (Elements 2019, Adobe).

\section{Statistical analysis}

The inter-rater reliability of two epileptologists was calculated by Cohen's kappa. Average SUVs of $\left[{ }^{11} \mathrm{C}\right]$ DPA713PET were compared between non-lesions and 
lesions using the Wilcoxon rank-sum test. The correlation analysis between $\left[{ }^{11} \mathrm{C}\right]$ DPA713PET in non-lesions and age was performed using Spearman's rank-order correlation analysis. The comparison of SUVr in lesions between chronic benzodiazepine (BZP) users and nonBZP users, as well as between patients with sedation and patients without sedation was performed using a twosample $t$ test. The correlation analysis between SUVr in lesions and duration of epilepsy was performed using linear regression analysis. The comparison of TSPO uptake and seizure frequency or etiology was performed using one-way analysis of variance (Bonferroni). The correlation analysis between the CD68 or GFAP-positive area and DPA713 uptake was performed using Spearman's rank-order correlation. $P$ values $<0.05$ were considered significant. Statistical analysis was performed using STATA version 15.1 (Stata Corp.).

\section{Results}

\section{Demographics}

Twenty-seven patients (mean age: $11.3 \pm 6.2$ years, male/ female: 17/10) were included in this study. The participants' demographics are shown in Table 1 . The mean seizure onset age was $4.2 \pm 4.1$ years. Twenty-two patients were diagnosed with focal epilepsy. Four patients who were diagnosed with symptomatic West syndrome showed epileptic spasms with a focal epileptogenic zone. One patient was diagnosed with Landau-Kleffner syndrome (LKS). All patients, except for one, took one or more antiepileptic drugs, including benzodiazepines (six patients). Nineteen patients had definite etiologies: tuberous sclerosis (TSC), eight; hemimegalencephaly (HME) with contralateral focal cortical dysplasia (FCD), one; FCD, one; encephalitis, two; Sturge-Weber syndrome, one; cavernous hemangioma, one; hippocampal sclerosis, one; cerebral infarction, two; low-grade glioma, one; and 1p36 deletion syndrome with pachygyria, one. Structure MRI showed focal abnormalities, such as cortical thickness, focal atrophy, and high intensity, in 18 patients. A total of 20 patients underwent interictal FDG-PET, and 15 (75.0\%) patients showed focal hypometabolism. $\left[{ }^{11} \mathrm{C}\right]$ DPA713PET, which was performed during the interictal period, was positive in the epileptogenic zone in $23(85.1 \%)$ patients (Table 2). All MRIpositive patients showed $\left[{ }^{11} \mathrm{C}\right]$ DPA713PET uptake in accordance with abnormal lesions on MRI. Five out of nine MRI-negative patients showed specific uptake patterns of $\left[{ }^{11} \mathrm{C}\right]$ DPA713. The inter-rater reliability between two epileptologists was $92.6 \%$ agreement $(\mathrm{kappa}=0.63)$. All patients, except for one mixed binder, were high-affinity binders for TSPO SNP.

\section{Qualitative $\left[{ }^{11} \mathrm{C}\right]$ DPA713PET image analysis}

Figure $1 \mathrm{a}-\mathrm{f}$ shows comparisons among MRI, FDG-PET, and $\left[{ }^{11} \mathrm{C}\right]$ DPA713PET images in representative six patients. Patient 2, who had ulegyria in the right occipital cortex, showed TSPO radioligand uptake in the right occipital and in the bilateral temporal area (Fig. 1a). Patient 3, who had low-grade gliomas in the right lateral temporal area, showed TSPO radioligand uptake in the tumor and in the right hippocampus (Fig. 1b). Patient 5, who had right hippocampal sclerosis, showed subtle changes on MRI and bilateral hypometabolism on FDGPET; however, $\left[{ }^{11} \mathrm{C}\right]$ DPA713 uptake showed prominent increases in the right hippocampus (Fig. 1c). Patient 9, who had 1 p36 deletion syndrome with right pachygyria, showed hypometabolic lesions in the right parietal and temporal cortex by FDG-PET (Fig. 1d), and $\left[{ }^{11} \mathrm{C}\right]$ DPA713PET clearly showed the right hemispheric distribution. In the TSC patient with multi-foci (patient 10; Fig. 1e), $\left[{ }^{11} \mathrm{C}\right]$ DPA713PET-positive areas were consistent with hypometabolic area indicated by FDG-PET. Although patient 15 (Fig. 1f), who had refractory seizures after herpes encephalitis, showed neuronal loss and atrophy in the left temporal area, where FDG-PET revealed broad hypometabolism, TSPO distribution was localized in the anterior temporal area.

Patient 19 had LKS, and EEG showed bilateral continuous spikes and waves predominantly in the right hemisphere (Fig. 1g). Although he showed normal MRI findings (Fig. 1h), TSPO PET found increased $\left[{ }^{11} \mathrm{C}\right]$ DPA713 uptake in the bilateral postcentral gyri and right hippocampus (Fig. 1i). His language cognition was improved by intravenous corticosteroid therapy.

$\left[{ }^{11} \mathrm{C}\right]$ DPA713PET-positive rate, which was the percentage of patients with abnormal uptake, in each etiology group were described as follows: (1) MRI-negative: $55.5 \%$ (5/9); (2) vascular lesions, such as cavernous hemangioma and Sturge-Weber syndrome: 100\% (2/2); (3) gliosis (hippocampal sclerosis and post encephalopathy): $100 \%$ (3/3); (4) tumor (low-grade gliomas): $100 \%$ (1/1); and (5) cortical malformation (FCD, HME, and cortical tuber in TSC): 100\% (10/10).

\section{Quantitative $\left[{ }^{11} \mathrm{C}\right]$ DPA713 binding analysis}

The quantitative binding analysis revealed no significant differences in the SUVr of $\left[{ }^{11} \mathrm{C}\right]$ DPA713 in the nonlesion regions among different cortices (average SUVr: $0.99 \pm 0.13$ in the temporal cortex, $1.03 \pm 0.16$ in the occipital cortex, $0.96 \pm 0.13$ in the parietal cortex, and 0.99 \pm 0.15 in the frontal cortex). In addition, the average DPA713-SUVr in non-lesions shows no association with age $(r=-0.366, P=0.06)$. The average DPA713-SUVr in the lesion ROIs $(1.37 \pm 0.16)$ was significantly increased compared with that in the non-lesion ROIs (1.05 \pm 0.10 ; Fig. $2 \mathrm{~b}, P<0.001$ ).

The median DPA713-SUVr values in the lesion did not differ according to seizure frequencies (no or yearly seizure, $1.43 \pm 0.19$; monthly seizure, $1.44 \pm 0.20$; weekly 
Table 1 Patient characteristics

\begin{tabular}{|c|c|c|c|c|c|c|c|c|c|}
\hline Patient & $\begin{array}{l}\text { Age, } \\
\text { years }\end{array}$ & Sex & $\begin{array}{l}\text { weight } \\
(\mathrm{kg})\end{array}$ & $\begin{array}{l}\text { Age of } \\
\text { onset (y) }\end{array}$ & $\begin{array}{l}\text { Epilepsy diagnosis } \\
\text { (localization) }\end{array}$ & AEDs & $\begin{array}{l}\text { Seizure } \\
\text { frequency }\end{array}$ & Seizure Types & Etiology \\
\hline 1 & 17 & M & 53.6 & 6 & $\mathrm{FE}(\mathrm{L}-\mathrm{F})$ & LTG, VPA, and ZNS & Yearly & Versive seizure & - \\
\hline 2 & 10 & M & 35.5 & 5 & FE (R-O) & $\begin{array}{l}\text { CLB, VPA, SLM, and } \\
\text { PER }\end{array}$ & Daily & CPS, SPS & Ulegyria \\
\hline 3 & 22 & M & 68.3 & 19 & $F E(R-T)$ & LEV & Monthly & CPS & $\begin{array}{l}\text { Tumor (low } \\
\text { grade glioma) }\end{array}$ \\
\hline 4 & 6 & M & 34.9 & 4 & $\mathrm{FE}(\mathrm{R}-\mathrm{F})$ & - & Monthly & Versive seizure & $\begin{array}{l}\text { Autoimmune } \\
\text { encephalitis }\end{array}$ \\
\hline 5 & 14 & $F$ & 53.7 & 9 & $\mathrm{FE}(\mathrm{R}-\mathrm{T})$ & LEV and CBZ & Daily & CPS & $\begin{array}{l}\text { Hippocampal } \\
\text { sclerosis }\end{array}$ \\
\hline 6 & 4 & M & 15.1 & 0.5 & WS & $\begin{array}{l}\text { VPA, ZNS, ESM, and } \\
\text { LTG }\end{array}$ & Daily & $\begin{array}{l}\text { Tonic seizure, } \\
\text { epileptic spasms }\end{array}$ & TSC \\
\hline 7 & 3 & $\mathrm{~F}$ & 18.8 & 0.3 & WS & $\begin{array}{l}\text { VGB, VPA, LEV, and } \\
\text { GBP }\end{array}$ & Daily & $\begin{array}{l}\text { Tonic seizure, } \\
\text { epileptic spasms }\end{array}$ & TSC \\
\hline 8 & 3 & M & 14.7 & 0.6 & $F E(L-F)$ & PB and LTG & Daily & hypermotor seizure & TSC2 mutation \\
\hline 9 & 13 & $F$ & 29.0 & 0.2 & $\mathrm{FE}(\mathrm{R}-\mathrm{F})$ & LTG, VPA, AZA, LCM & Weekly & sGTC & 1p36 deletion \\
\hline 10 & 9 & M & 24.7 & 5 & WS & VPA and LTG & Daily & $\begin{array}{l}\text { Tonic seizure, } \\
\text { epileptic spasms }\end{array}$ & TSC \\
\hline 11 & 11 & M & 38.1 & 6 & $\mathrm{FE}(\mathrm{L}-\mathrm{O})$ & $C B Z, P B$, and PER & Daily/weekly & Visual SPS/sGTC & $\begin{array}{l}\text { Cerebral } \\
\text { infarction }\end{array}$ \\
\hline 12 & 16 & $F$ & 47.5 & 3 & $F E(R-F)$ & $\begin{array}{l}\text { LEV, LTG, CLB, and } \\
\text { PER }\end{array}$ & Monthly & SPS & $\begin{array}{l}\text { Cavernous } \\
\text { hemangioma }\end{array}$ \\
\hline 13 & 25 & M & 48.0 & 0.5 & $\mathrm{FE}(\mathrm{R}-\mathrm{F})$ & $\begin{array}{l}\text { TPM, CLB, LEV, and } \\
\text { PER }\end{array}$ & Yearly & sGTC & $\begin{array}{l}\text { Sturge-Weber } \\
\text { syndrome }\end{array}$ \\
\hline 14 & 8 & M & 23.0 & 4 & $F E(L-F)$ & ZNS and CBZ & Daily & Automatism & - \\
\hline 15 & 5 & M & 18.6 & 3 & FE (L-T) & PB and CZP & Daily & $\begin{array}{l}\text { Epileptic spasms, } \\
\text { CPS }\end{array}$ & $\begin{array}{l}\text { Herpes } \\
\text { encephalitis }\end{array}$ \\
\hline 16 & 11 & M & 35.9 & 7 & $\mathrm{FE}(\mathrm{LR}-\mathrm{F})$ & LTG and CBZ & Weekly & Versive seizure & - \\
\hline 17 & 16 & $\mathrm{~F}$ & 43.9 & 4 & $F E(R-F)$ & VPA & Daily & Hypermotor seizure & TSC \\
\hline 18 & 11 & M & 33.7 & 1.6 & $F E(R-F)$ & CBZ and VPA & - & Versive seizure & TSC \\
\hline 19 & 10 & M & 58.5 & 5 & LK & $\begin{array}{l}\text { CZP, ESM, LCM, } \\
\text { DZP, and VPA }\end{array}$ & Yearly & CPS & - \\
\hline 20 & 7 & $\mathrm{~F}$ & 20.1 & 1.5 & $\mathrm{FE}(\mathrm{LR}-\mathrm{F})$ & VPA, PHT, and ZNS & Daily & Hypermotor seizure & - \\
\hline 21 & 22 & $\mathrm{~F}$ & 42.0 & 2.3 & $F E(R-F)$ & $\begin{array}{l}\text { PHT, VPA, LTG, and } \\
\text { PER }\end{array}$ & Monthly & SPS & TSC \\
\hline 22 & 13 & M & 29.1 & 3.4 & FE (L-P) & LTG, ZNS, and VPA & Daily & Hypermotor, tonic & FCD \\
\hline 23 & 19 & M & 61.5 & 13 & FE (L-T) & CBZ and PER & Yearly & Visual aura sGTC & - \\
\hline 24 & 11 & M & 45.6 & 1.3 & $F E(L-F)$ & LEV, SLM, and NZP & Weekly & brief tonic (CPS) & - \\
\hline 25 & 6 & $\mathrm{~F}$ & 19.6 & 2.4 & $\mathrm{FE}(\mathrm{R}-\mathrm{F})$ & VPA and PER & - & $\begin{array}{l}\text { subclinical seizure } \\
\text { only }\end{array}$ & TSC \\
\hline 26 & 1 & $\mathrm{~F}$ & 8.6 & 0.8 & WS & VGB & Daily & epileptic spasms & $\mathrm{HME}+\mathrm{FCD}$ \\
\hline 27 & 13 & $\mathrm{~F}$ & 53.8 & 5.4 & $F E(L-F)$ & $\begin{array}{l}\text { TPM, LEV, PER, and } \\
\text { LTG }\end{array}$ & Weekly & SPS & - \\
\hline
\end{tabular}

AEDs antiepileptic drugs, $F$ Female, $M$ male, $F E$ focal epilepsies, $L$ - left, $R$ - right, $F$ frontal, $T$ temporal, $O$ occipital, $P$ parietal, $W S$ West syndrome, $L K$ Landau-Kleffner syndrome, LTG lamotrigine, VPA valproic acid, ZNS zonisamide, CLB clobazam, SLM sultiam, PER perampanel, $L E V$ levetiracetam, CBZ carbamazepine, ESM ethosuximide, VGB vigabatrin, GBP gabapentin, $P B$ phenobarbital, $A Z A$ acetazolamide, $L C M$ lacosamide, TPM topiramate, DZP diazepam, $P H T$ phenytoin, CPS complex partial seizures, SPS simple partial seizures, $S G T C$ secondarily generalized tonic-clonic convulsion, TSC tuberous sclerosis complex, FCD focal cortical dysplasias, HME hemimegalencephaly

seizure, $1.37 \pm 0.06$; daily seizure, $1.42 \pm 0.19, P=0.48$; Fig. 3a). In addition, the median DPA713-SUVr values in the lesion did not differ between chronic BZP users and non-BZP users $(1.18 \pm 0.194,1.293 \pm 0.435, P=0.551)$, and between patients with sedation and patients without sedation $(1.375 \pm 0.05,1.367 \pm 0.191, P=0.920)$. Moreover, median DPA713-SUVr values in the lesion did not correlate to the duration of epilepsy $(P=0.669)$. 
Table 2 Neuroimaging findings and pathological data

\begin{tabular}{|c|c|c|c|c|c|c|c|}
\hline Patients & MRI & EEG/MEG & FDG-PET $^{\mathrm{a}}$ & $\begin{array}{l}{\left[{ }^{11} \mathrm{C}\right] \mathrm{DPA} 713 \mathrm{PET} \text { increased }} \\
\text { uptake }\end{array}$ & $\begin{array}{l}\text { sedation during } \\
\text { DPA713PET }\end{array}$ & $\begin{array}{l}\text { TSPO, } \\
\text { SNP }\end{array}$ & Surgery ${ }^{b}$ \\
\hline 1 & Normal & $L-F$ & Normal & No specific uptake & - & $\mathrm{HAB}$ & Focal ECoG (I) \\
\hline 2 & $\mathrm{R}-\mathrm{O}$ & R-TO & R-TO & $\mathrm{R}-\mathrm{O}, \mathrm{R}>\mathrm{L}-\mathrm{T}$ & - & $\mathrm{HAB}$ & Focal resection(I) \\
\hline 3 & R-T & $R-T$ & R-T & $R-T$ & - & $\mathrm{HAB}$ & Focal resection(I) \\
\hline 4 & atrophy & $\mathrm{Bi}-\mathrm{F}$ & R-T & R-cingulate & PTB, LMP & $\mathrm{HAB}$ & - \\
\hline 5 & $R-T$ & $R-T$ & $\mathrm{Bi}-\mathrm{T}$ & $R-T$ & - & $\mathrm{HAB}$ & Focal resection (I) \\
\hline 6 & Multi (L-T) & L-CTO & N.D & L-TPO & THP,MDZ & $\mathrm{HAB}$ & $\begin{array}{l}\text { P-quadrantectomy } \\
\text { (III) }\end{array}$ \\
\hline 7 & Multi & $\mathrm{Bi}-\mathrm{FTO}$ & N.D & $\mathrm{Bi}-\mathrm{F}$ & THP,MDZ & $\mathrm{HAB}$ & - \\
\hline 8 & Normal & $R-F, L-F$ & Normal & No specific uptake & TRF, THP & $\mathrm{HAB}$ & Callosotomy (IV) \\
\hline 9 & R-FTP & $\mathrm{R}-\mathrm{FC}$ & R-TP & R-FTP & MDZ,THP,PTZ & $\mathrm{HAB}$ & - \\
\hline 10 & $L-F, R-T$ & $L-F$ & $\mathrm{Bi}-\mathrm{F}$ & $L-F$ & THP,PTZ & MAB & Focal resection (II) \\
\hline 11 & $O(R>L)$ & $L-O$ & Bi-OPT & $\mathrm{Bi}-\mathrm{O}$ & - & $\mathrm{HAB}$ & Focal resection $(|\rightarrow|||)$ \\
\hline 12 & $\mathrm{R}-\mathrm{F}$ & $\mathrm{R}-\mathrm{C}$ & $\mathrm{R}-\mathrm{FT}$ & $R-F$ & - & $\mathrm{HAB}$ & - \\
\hline 13 & $\mathrm{R}-\mathrm{F}$ & $L-F$ & $\mathrm{R}-\mathrm{FT}$ & $\mathrm{R}-\mathrm{F}$ & - & $\mathrm{HAB}$ & - \\
\hline 14 & Normal & $\mathrm{Bi}-\mathrm{F}$ & Normal & $L-F$ & - & $\mathrm{HAB}$ & - \\
\hline 15 & $L-T$ & Diffuse & $L-T$ & $L-T$ & THP & $H A B$ & Focal resection (II) \\
\hline 16 & Normal & $L-F, R-F T$ & Normal & No specific uptake & THP, MDZ & $\mathrm{HAB}$ & - \\
\hline 17 & MT & $R-T$ & $R-F, L-P, T$ & R-insula, O & DZP & $\mathrm{HAB}$ & Focal resection (III) \\
\hline 18 & MT & $L-T, P, O$ & N.D & $R-F, L-F$ & THP,MDZ,PTZ & $\mathrm{HAB}$ & - \\
\hline 19 & Normal & CSWS $(R>L)$ & N.D & Bi-P, R-T & PTB,THP,MDZ,PTZ & $\mathrm{HAB}$ & $\begin{array}{l}\text { - (corticosteroid } \\
\text { effective) }\end{array}$ \\
\hline 20 & Normal & $\mathrm{Bi}-\mathrm{F}$ & L-FP & $R>L$ insula, cingulate & PTB,THP,MDZ,PTZ & $\mathrm{HAB}$ & - \\
\hline 21 & MT, SEN & $\mathrm{R}-\mathrm{F}$ & N.D & R-insula $\sim B G, L-F, P$ & PTB & $\mathrm{HAB}$ & - \\
\hline 22 & L-TPO FCD & $L-P C$ & L-TPO & L-TPO & RIS,PTB & $H A B$ & - \\
\hline 23 & Normal & $\begin{array}{l}\text { L-T/L-P } \\
\text { (MEG) }\end{array}$ & N.D & L-O, L>R hippocampus & - & $\mathrm{HAB}$ & EcoG L-O \\
\hline 24 & Normal & Bi-F-Diffuse & $\begin{array}{l}\text { L- } \\
\text { hemisphere }\end{array}$ & L-FT & DZP & $\mathrm{HAB}$ & - \\
\hline 25 & MT & $\begin{array}{l}L-F, R-F \\
\text { multi }\end{array}$ & N.D & $R-F, L-F$, cingulate & PTB & $\mathrm{HAB}$ & - \\
\hline 26 & $\begin{array}{l}\text { L-HME, R-TO } \\
\text { FCD }\end{array}$ & R-TO spike & L-FTP & L-deep WM, R-OT & THP,MDZ & $\mathrm{HAB}$ & - \\
\hline 27 & Normal & L-insula & Normal & No specific uptake & - & HAB & - \\
\hline
\end{tabular}

$M R I$ magnetic resonance imaging, EEG electroencephalogram, MEG magnetoencephalography, FDC fludeoxyglucose $\mathrm{F}^{18}, P E T$ positron emission tomography, $T E S P$ translocator protein $18 \mathrm{kDa}, R$ right, $S N P$ single-nucleotide polymorphisms, $L$ left, $P$ posterior, $T$ temporal, $O$ occipital, $M T$ multiple tubers, $H M E$

hemimegalencephaly, FCD focal cortical dysplasias, Bi bilateral, BG basal ganglia, WM white matter, CSWS continuous spikes and waves during sleep, PTB

Pentobarbital, THP Thiopental, MDZ midazolam, LMP Levomepromazine, RIS Risperidone, TRF Triclofos, PTZ Pentazocine, DZP diazepam, HAB high-affinity binders.

The DPA713-SUVr of the lesion was compared between etiologies, and it was found that DPA713-uptake tended to be most prominent in gliosis and cortical malformation, although the difference was not significant (Fig. $3 \mathrm{~b}, P=0.24$ ).

In the histopathological study, the epileptogenic lesion showed remarkable accumulation of activated microglia indicated by CD68 immunostaining and that of reactive astrocytes indicated by GFAP immunostaining in all seven patients who underwent focal resection. (Representative findings of patient 17 are presented in Fig. 4a- e.) In addition, DPA713 uptake in the lesion ROIs was significantly correlated with the CD68-positive area $(r=$ 0.857, $P<0.05$; Fig. 4f), but not with the GFAP-positive area $(r=-0.286, P=0.53$; data not shown), suggesting that increased $\left[{ }^{11} \mathrm{C}\right]$ DPA713 uptake correlates with the accumulation of activated microglia.

\section{Discussion}

In this study, we found that (1) neuroinflammation defined as TSPO PET positivity was recognized in various child-onset foal epilepsies, including epileptic 

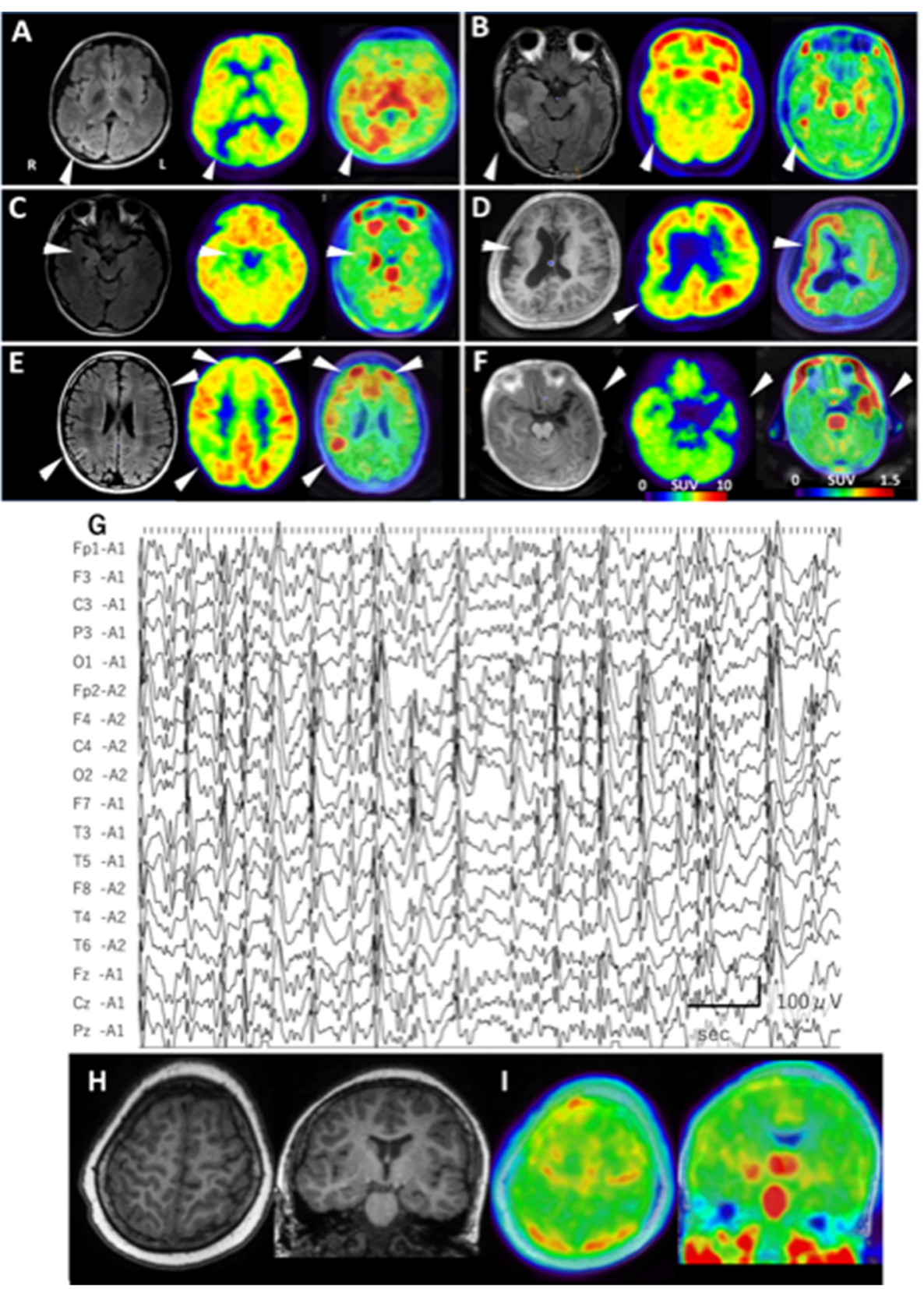

Fig. 1 Neuroimaging data of six selected patients (a-f). Left, MRI; middle, FDG-PET; right, $\left[{ }^{11} \mathrm{C}\right]$ DPA713PET. a Patient 2. MRI showed ulegyria in the right occipital cortex. In this area, hypometabolism, as indicated by FDG-PET, and increased $\left[{ }^{11} \mathrm{C}\right]$ DPA713 uptake, as indicated by TSPO PET, were observed. b Patient 3 had low-grade gliomas with a high-intensity area in the middle temporal cortex, as indicated by FLAIR-MRI. Increased $\left[{ }^{11} \mathrm{C}\right]$ DPA713 uptake on TSPO PET was clearly visible compared with hypometabolism on FDG-PET. C, In patient 5, the right hippocampus showed subtle atrophy, but no obvious high intensity, on FLAIR-MRI and hypometabolism on FDG-PET. In addition, the right hippocampus showed clearly increased $\left[{ }^{11} \mathrm{C}\right]$ DPA713 uptake on TSPO PET. $\mathbf{d}$ Patient 9 with $1 \mathrm{p} 36$ deletion syndrome showed broad cortical malformation in the right hemisphere on T1-MRI. Although FDG-PET showed hypometabolism in the right temporo-occipital area and hypermetabolism in the right insula-inferior frontal area, TSPO PET demonstrated clearly increased $\left[{ }^{11} \mathrm{C}\right]$ DPA713 uptake in the right hemispheric cortex. e Patient 10 with TSC showed high intensity in the left frontal and right parietal cortex on FLAIR-MRI, suggesting cortical tubers. FDG-PET showed patchy hypometabolism, but the increased uptake area of $\left[{ }^{11} \mathrm{C}\right]$ DPA713 was easy to determine using TSPO PET. F, Patient 15 had atrophy caused by herpes encephalitis in the left temporal cortex and hippocampus on MRI. Although FDG-PET showed broad hypometabolism not only in the left temporal cortex but also in the right temporal cortex, TSPO PET found that the increased uptake area of $\left[{ }^{11} \mathrm{C}\right]$ DPA713 was restricted in the left temporal cortex. Findings obtained from patient 19, who had Landau-Kleffner syndrome (g-i). EEG showed a continuous spike-wave pattern, and the bilateral-centro-parieto-temporal discharges were predominantly observed in the right hemisphere (g). MRI showed no obvious abnormality (h), and TSPO PET revealed increased $\left[{ }^{11} \mathrm{C}\right]$ DPA713 uptake in the bilateral postcentral gyri and right hippocampus (i) 


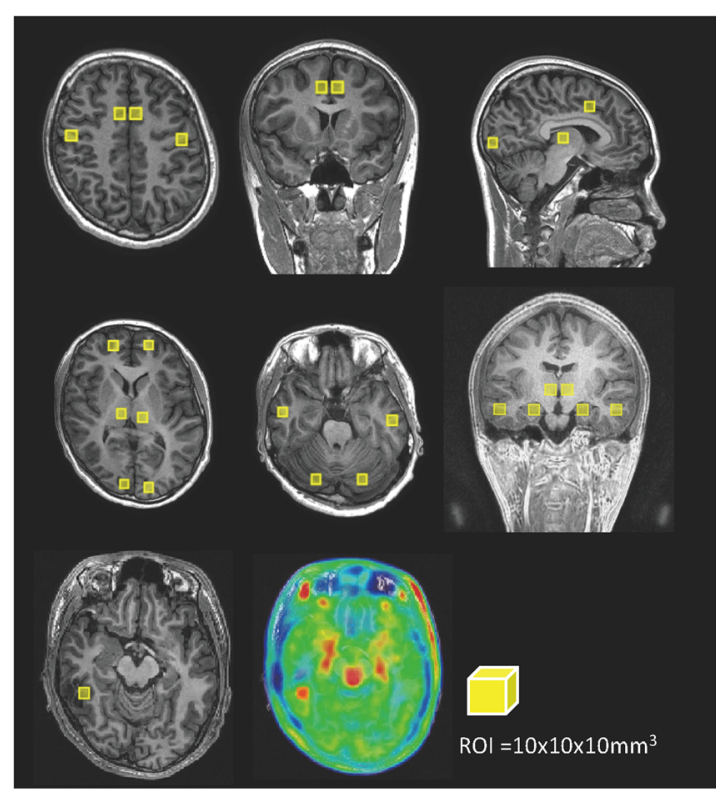

A

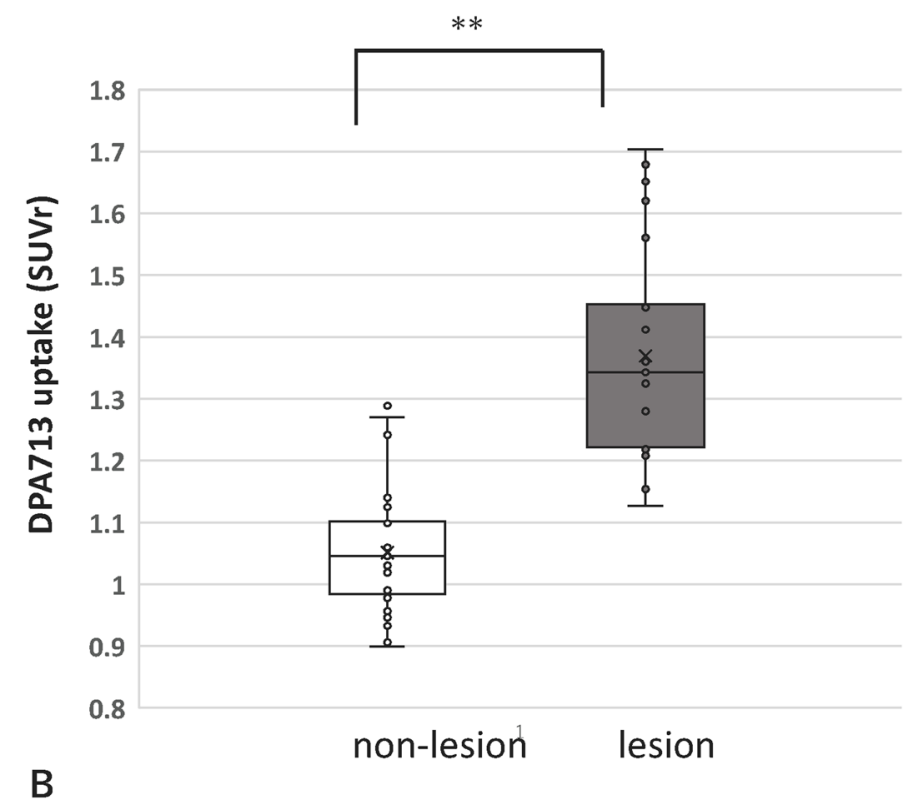

Fig. 2 ROI-based analysis. a Each ROI from non-lesional cortical areas is shown in the upper and middle rows. Each ROI of DPA713PET is located on the MRI (left in bottom row) oriented merged area (middle in the bottom row). b Comparisons of SUVr of DPA713PET between lesions and non-lesions. The SUVr of DPA713PET was significantly higher in the lesion than in the non-lesion $(P<0.001)$

encephalopathy, and (2) in several resected tissues, TSPO radioligand uptake tended to be correlated with microglial accumulation. The validity of TSPO PET as a marker for neuroinflammation was confirmed by histopathological findings. To the best of our knowledge, this study is the first to demonstrate the clinical usefulness of TSPO PET in the detection of neuroinflammation in child-onset epilepsy with various etiologies.

TSPO PET has confronted problems such as high non-specific binding and the presence of low-affinity binders [25]. In this study, using $\left[{ }^{11} \mathrm{C}\right]$ DPA713, which is superior in the signal to noise ratio [26], we easily

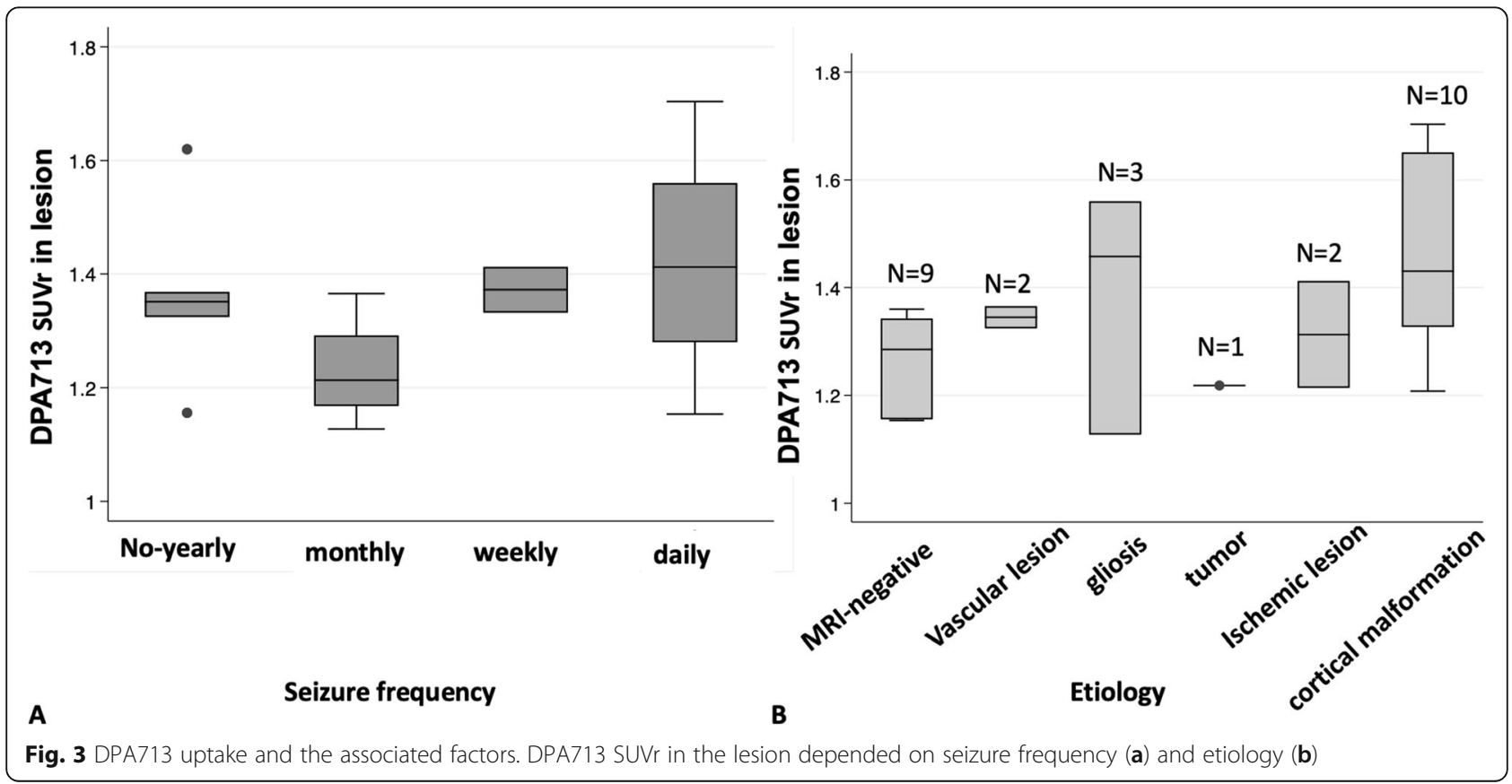



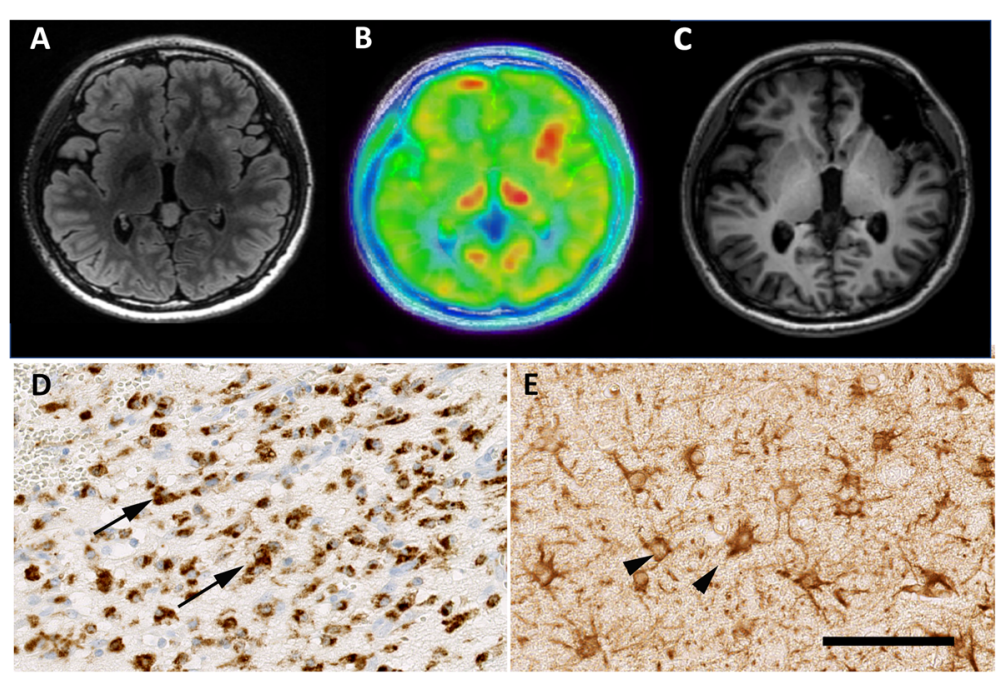

$\mathbf{F}$

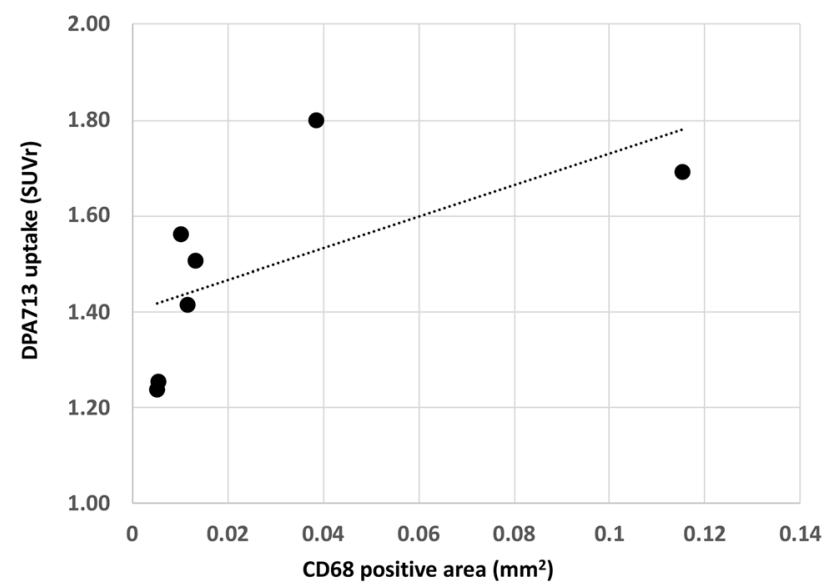

Fig. 4 Neuroimaging and distribution of activated microglia and reactive astrocytes in the resected tissues (a-b). a FLAIR MRI, b DPA713PET, and c post-surgical T1-MRI for Patient 17 with TSC. This patient showed multiple cortical tubers (a, b). After examining the epileptogenic zone with subdural EEG, the focal resection was performed (c). In the resected tissue, immunohistochemistry for CD68 (d) and GFAP (e) showed prominent accumulation of activated microglia and reactive astrocytes. However, due to multiple lesions, although the seizure frequency was reduced, it persisted. f Association between the CD68 positive area and DPA713 uptake. DPA713 uptake had a positive association with the CD68 positive area $\left(r=0.857, P<0.05\right.$. The $X$-axis indicates the CD68 positive area (area $\left./ \mathrm{mm}^{2}\right)$, and $Y$-axis indicates DPA uptake (SUVr). Scale bar, $100 \mu \mathrm{m}$

detected the difference in the SUVr between the nonlesion and the epileptic lesion. One previous study found that low-affinity binders accounted for $4 \%$ in the Japanese population [25]; however, there were no lowaffinity binders in our present study. Therefore, TSPO PET could be very useful for neuroinflammation imaging, especially in the East Asian populations.

The brain regions with high TSPO ligand uptake in healthy controls are the pituitary gland, midbrain, thalamus, and basal ganglia, and there is relatively low TSPO ligand uptake in the cortex and cerebellum. Notably, Kumar et al. compared TSPO distribution between children and adults and found that TSPO ligand uptake in the midbrain and thalamus increased with age [23]. Specifically, TSPO PET showed an assessable signal to noise ratio in child and adolescent patients in our present study, although there was no correlation between age and TSPO ligand uptake in non-lesions (data not shown). Notably, in early child-onset epilepsy, it is difficult to determine the FCD with MRI at onset because of the immaturity of myelination [27]. Therefore, in addition to FDG-PET [28], TSPO PET could be a useful neuroimaging approach for diagnosing early-onset child epilepsy.

Neuroinflammation-associated pathological events in epilepsy include two main scenarios: (1) neuroinflammation is commonly present in the epileptogenic foci in broad etiologies, and (2) neuroinflammation is induced by repetitive epileptic activity with frequent spikes and seizure propagation in the associated brain regions. Several studies have reported the usefulness of TSPO PET in epilepsies, i.e., Rasmussen's encephalitis [29], cerebral 
vasculitis [30], and intractable epilepsy due to encephalitis [31], and temporal lobe epilepsy (TLE) with hippocampal sclerosis [32]. In this study, we found that neuroinflammation contributed to focal epilepsy with wide-ranging etiologies, including tumors, ischemic lesions, and cortical malformations. Therefore, neuroinflammation in the epileptic focus might be implicated in the intractability of epilepsy.

Regarding temporal changes in microglial activation induced by seizures, $\left[{ }^{18} \mathrm{~F}\right]$ flutriciclamide TSPO PET showed that microglial activation increased at $24 \mathrm{~h}$, peaked in $5-15$ days, and decreased during the chronic phase [33, 34]; moreover, it was found that subacute neuroinflammation $\sim 36 \mathrm{~h}$ after seizures in a patient with frontal lobe epilepsy was associated with greater $\left[{ }^{11} \mathrm{C}\right] \mathrm{PK} 11195$ uptake and more spatial extension in the post-seizure period than in the seizure-free period [35]. These findings suggested that microglial activation increases following a single seizure and might contribute to further epileptogenesis. In fact, microglia promote development and aggravation of epilepsy by aberrant synaptic pruning and changes in the neuronal network [36, 37]. In addition, Webster et al. have reported an agespecific vulnerability to seizures and inflammatory stimuli in children [38]. As the developing childhood brains showed higher chemokine and cytokine levels, slow glutamate clearance, and a depolarizing role of the GABA receptor, the increased seizure susceptibility may lead to high intractability in child-onset epilepsy. Our study found no significant differences in TSPO ligand uptake based on seizure frequencies, nor epilepsy duration, probably because of the different periods after last seizure, or effects of antiepileptic drugs. Although benzodiazepine drugs [39], which bind to TSPO, might affect TSPO radioligand binding, there were no differences in TSPO radioligand binding between six patients who took benzodiazepines and others who did not, and between patients with sedation and them without sedation in our study. However, as most of patients in this study showed refractory epilepsy, with obvious structural abnormality, frequent seizures, and long duration of epilepsy, the contribution of BZPs and sedative drugs to the TSPO uptake could be negligible.

Compared with FDG-PET, the increased TSPO uptake area corresponded to hypometabolic area by FDG-PET. In general, neuroinflammation increased energy consumption, where microglia upregulate GLUT1 to facilitate glucose uptake and drive the glycolysis pathway [40]. However, many previous studies reported that hypometabolism in FDG-PET is useful to localize seizure foci in various epilepsy [41] and has no correlation to neuronal loss [42]. Boison et al. reported that excessive synaptic activity causes a rapid drop in glucose, and during the excessive energy demands of seizures, astrocyte- derived lactate become an essential energy source for neurons. Therefore, patients with epilepsy are characterized by increased glucose uptake and metabolism during seizures, whereas the interictal periods are characterized by reduced glucose uptake and hypometabolism [43]. Consequently, the hypermetabolism by FDG-PET in epileptogenic zone was also reported [44].

A previous study demonstrated that TSPO ligand uptake levels were strongly correlated with the accumulation of microglia and reactive astrocytes in a rat model of TLE [45]. In our study, although the TSPO ligand uptake was positively correlated with the density of microglia, it should be noted that the sample size was small and showed large variability; TSPO ligand uptake was also not positively correlated with that of reactive astrocytes. In Brackhan's study, the rat model was assessed at the acute phase after single status epilepticus insults [45]; however, in our study, most patients were assessed during the chronic stage. The patients whose pathology was evaluated showed frequent seizures; therefore, their TSPO PET included factors of the chronic and acute stages. In Nguyen's study, TSPO was strongly detected in microglia and reactive astrocytes during the acute and chronic phases, respectively [46]. As Sanz [47] mentioned, epileptic seizures and inflammatory mediators in microglia and astrocytes form a vicious positive feedback loop. Further studies with larger samples are needed to verify the essential roles of microglia and astrocytes in epilepsy.

In addition, Gershen et al. reported significantly increased $\left[{ }^{11} \mathrm{C}\right]$ PBR28 PET uptake in the bilateral temporal regions in TLE patients compared with healthy controls $[32,48]$. A study using a kainic acid-induced rat SE model found that TSPO distribution could be used to evaluate microglial activation, astrocyte reactivity, and cell loss at several time points in both acute and chronic phases. As TSPO ligand uptake increased in the epileptogenic lesion most of our patients, the usefulness of TSPO-PET for the indication of the epileptogenic zone is convincing. However, at the same time, TSPO uptake was increased in the propagated area, such as the ipsilateral hippocampus and/or contralateral hippocampus. As patients 2 and 3 were seizure free after focal resection of the right occipital lobe and the tumor in the right temporal lobe, respectively, neuroinflammation in the ipsilateral hippocampus did not suggest strong epileptogenicity. As the TSPO ligand levels increased in reactive astrocytes and microglia, TSPO PET could be used to reveal secondary gliosis along with primary inflammation [49]. Therefore, we should confirm the epileptogenicity by subdural- or stereo-EEG in the TSPO uptake area.

Temporal changes in neuroinflammation after seizures have been demonstrated [33], and TSPO PET could be used to find a good candidate for anti-inflammatory 
therapy. LKS is a rare form of childhood epilepsy characterized by loss of language comprehension with continuous spike and waves and rare seizures [50]. The patient with LKS in this study showed bilaterally increased uptake of TSPO ligand, corresponding with frequent EEG spikes, and the symptom was improved by the corticosteroid therapy performed after identifying neuroinflammation by TSPO PET. Further studies are needed to compare neuroinflammation between pre- and posttherapy to determine whether neuroinflammation is reduced by corticosteroids.

This study had several limitations. First, we did not obtain data regarding normal TSPO distribution in agematched healthy children. As children are more radiosensitive than adults [51] and are at higher risk of thyroid tumors or benign pituitary adenoma [52] [53], the PET study could not be performed on healthy children, and we did not calculate the absolute radioligand value from the arterial blood samples. Second, since there are no regions in the brain that do not express TSPO [54], the reference region cannot be defined in terms of pharmacokinetics [19]. Therefore, it is impossible to calculate distribution volume or distribution volume ratios by performing pharmacokinetic analysis without arterial blood data. In both animal and clinical studies, either the thalamus [19] or cerebellum [24, 55] has been used as a pseudo-reference for calculating the SUVr. In this study, we used the cerebellum as a reference to standardize the uptake values and allow comparisons between patients. The rationale of using the cerebellum as an uptake reference is that focal epilepsy, including tuberous sclerosis, targeted in this study is known to leave no lesions in the cerebellum, and MRI did not show any abnormalities in the cerebellum in our patients. In epileptic lesions, cerebral blood flow is generally reduced during the interictal period. If the tracer uptake is biased by cerebral blood flow, it is inevitable that the uptake will decrease in epileptogenic lesions. However, DPA713 uptake increases rather than decreases in the lesions. Thus, semi-quantitative evaluation by SUVr is still useful, despite some possibility that SUVr was influenced by a severe hemispheric cortical abnormality. In this clinical study, SUVr was evaluated in the late time phase 40-60 min after the administering the ligand. When evaluating the SUV in the late static phase of $\left[{ }^{11} \mathrm{C}\right]$ DPA713 PET, more rigorous quantitative evaluation of brain inflammation can be performed; further studies are necessary to determine the correlation between the tracer distribution volume estimated from the full dynamic acquisition and SUV obtained from the late static phase. Moreover, we did not determine the extent of inflammation in this study. If the normal range of TSPO uptake is known, it will help in assessing the extent of the inflammation. Third, the sample size was not enough to compare TSPO ligand uptake among different etiologies, and the number of patients whose pathology could be examined was also limited. Therefore, further studies are needed to confirm our present findings in patients undergoing surgical intervention and those with focal epilepsy with a variety of etiologies.

\section{Conclusions}

This study found that $\left[{ }^{11} \mathrm{C}\right]$ DPA713 PET showed valuable sensitivity for detecting focal epileptogenic zones in child-onset focal epilepsy of various etiologies. Although the increased uptake of $\left[{ }^{11} \mathrm{C}\right]$ DPA713, which was significantly associated with microglial accumulation, revealed that neuroinflammation is a common neuropathological feature in child-onset focal epilepsy, the causal link to its refractory nature and the influence on cognitive functions remain unclear. Further research is needed to evaluate $\left[{ }^{11} \mathrm{C}\right]$ DPA713 in longitudinal studies and whole-brain analyses.

\section{Supplementary Information}

The online version contains supplementary material available at https://doi. org/10.1186/s12974-020-02055-1.

\section{Additional file 1: Supplementary Figure. A) Sphere volume-of-}

interest (VOI) ( $\varphi 5-15 \mathrm{~mm}$ ) was located on the epileptogenic foci resected by surgery or on the pathological region determined by MRI and on the corresponding region in the contralateral hemisphere. If there were multiple pathological lesions (e.g. cortical tuber), the lesion included in the epileptogenic zone was selected as the focus, and the contralateral control VOI was located in the normal apparent area based on the coregistered MRI. B) The time course of the Al of the patients were averaged. The graph shows the two groups comprising 14 subjects with unilateral foci: 10 patients were imaged from 0 to 60 minutes, and the remaining 4 patients were scanned from 30 to 90 minutes after the administration of the ligand. Bars represent the standard error of the mean

\section{Abbreviations}

EEG: Electroencephalography; PET: Positron emission tomography; MRI: Magnetic resonance imaging; SUV: Standard uptake value;

SUVr: Standardized uptake value ratio; TSPO: Translocator protein; DPA: N,Ndiethyl-2-(4-methoxyphenyl)-5,7-dimethylpyrazolo[1,5-a]pyrimidine-3acetamide; FDG-PET: ${ }^{18}$ F-2-deoxy-2-fluoro-D-glucose positron emission tomography; VOI: Volume-of-interest; ROI: Region of interest; CD68: Cluster of differentiation 68; GFAP: Glial fibrillary acidic protein; LKS: Landau-Kleffner syndrome; TSC: Tuberous sclerosis; HME: Hemimegalencephaly; FCD: Focal cortical dysplasia; TLE: Temporal lobe epilepsy

\section{Acknowledgments}

We thank all participants and Mrs. Nakamura for her assistance during the pathological examinations.

\section{Authors' contributions}

$\mathrm{KKS}, \mathrm{HK}$, and $\mathrm{JH}$ designed the study and prepared for the experiments. $\mathrm{RH}$ performed the experiments. KT and SN recruited the patients. KKS and HK analyzed the data. HK performed the surgeries and pathological

examinations. KKS and MT drafted the manuscript and prepared the figures. All authors reviewed and approved the manuscript.

\section{Funding}

This study was supported by JSPS KAKENHI (Grant Number, JP18K07843), the Novartis Research Grants, Takeda Science Foundation, the Eizai Scholarship 
and the Osaka University Program for the Support of Networking among Present and Future Researchers.

\section{Availability of data and materials}

The datasets used and analyzed during the current study are available from the corresponding author on reasonable request.

\section{Ethics approval and consent to participate}

All participants and/or their guardians provided written informed consent to participate in this study. This study was approved by the Institutional Review Board of Osaka University Hospital (No.16092-6) and was conducted according to the principles of the Declaration of Helsinki.

\section{Consent for publication}

Not applicable.

\section{Competing interests}

None of the authors has any conflict of interest to disclose.

\section{Author details}

'Department of Child Development, United Graduate School of Child Development, Osaka University, Suita, Osaka, Japan. ²Department of Pediatrics, Osaka University Graduate School of Medicine, Suita, Japan. ${ }^{3}$ Epilepsy Center, Osaka University Hospital, Suita, Japan. ${ }^{4}$ Department of Nuclear Medicine and Tracer Kinetics, Osaka University Graduate School of Medicine, Suita, Japan. ${ }^{5}$ Department of Neurosurgery, Osaka University Graduate School of Medicine, Suita, Japan. ${ }^{6}$ Department of Quantum Cancer Therapy Research Center for Nuclear Physics, Osaka University, Suita, Japan.

\section{Received: 14 July 2020 Accepted: 9 December 2020}

\section{Published online: 06 January 2021}

\section{References}

1. Ngugi AK, Bottomley C, Kleinschmidt I, Sander JW, Newton CR. Estimation of the burden of active and life-time epilepsy: a meta-analytic approach. Epilepsia. 2010:51:883-90

2. Vos T, Allen C, Arora M, Barber RM, Bhutta ZA, Brown A, et al. Global, regional, and national incidence, prevalence, and years lived with disability for 310 diseases and injuries, 1990-2015: a systematic analysis for the Global Burden of Disease Study 2015. Lancet. 2016;388:1545-602.

3. Scheffer IE, Berkovic S, Capovilla G, Connolly MB, French J, Guilhoto L, et al. ILAE classification of the epilepsies: position paper of the ILAE Commission for Classification and Terminology. Epilepsia. 2017;58:512-21.

4. Chen Z, Brodie MJ, Liew D, Kwan P. Treatment outcomes in patients with newly diagnosed epilepsy treated with established and new antiepileptic drugs:a 30-year longitudinal cohort study. JAMA Neurol. 2018;75:279-86.

5. Andersson PB, Perry VH, Gordon S. The kinetics and morphological characteristics of the macrophage-microglial response to kainic acidinduced neuronal degeneration. Neuroscience. 1991:42:201-14.

6. Eyo UB, Peng J, Swiatkowski P, Mukherjee A, Bispo A, Wu L-J. Neuronal hyperactivity recruits microglial processes via neuronal NMDA receptors and microglial P2Y12 receptors after status epilepticus. J Neurosci. 2014;34: 10528-40.

7. Wirenfeldt M, Clare R, Tung S, Bottini A, Mathern GW, Vinters HV. Increased activation of Iba1+ microglia in pediatric epilepsy patients with Rasmussen's encephalitis compared with cortical dysplasia and tuberous sclerosis complex. Neurobiol Dis. 2009;34:432-40.

8. Beach TG, Woodhurst WB, MacDonald DB, Jones MW. Reactive microglia in hippocampal sclerosis associated with human temporal lobe epilepsy. Neurosci Lett. 1995;191:27-30.

9. Boer K, Spliet WG, van Rijen PC, Redeker S, Troost D, Aronica E. Evidence of activated microglia in focal cortical dysplasia. J Neuroimmunol. 2006;173: 188-95.

10. Pardo CA, Vining EP, Guo L, Skolasky RL, Carson BS, Freeman JM. The pathology of Rasmussen syndrome: stages of cortical involvement and neuropathological studies in 45 hemispherectomies. Epilepsia. 2004;45: $516-26$

11. Sorel L, Dusaucy-Bauloye A. Findings in 21 cases of Gibbs' hypsarrhythmia; spectacular effectiveness of ACTH. Acta Neurol Psychiatr Belg. 1958;58:130-41.
12. Braestrup C, Squires RF. Specific benzodiazepine receptors in rat brain characterized by high-affinity $(3 \mathrm{H})$ diazepam binding. Proc Natl Acad Sci U S A. 1977;74:3805-9.

13. Banati RB. Visualising microglial activation in vivo. Glia. 2002;40:206-17.

14. Turkheimer FE, Rizzo G, Bloomfield PS, Howes O, Zanotti-Fregonara P, Bertoldo A, et al. The methodology of TSPO imaging with positron emission tomography. Biochem Soc Trans. 2015;43:586-92.

15. Kreisl WC, Fujita M, Fujimura Y, Kimura N, Jenko KJ, Kannan $P$, et al. Comparison of $\left[{ }^{11} \mathrm{C}\right]-(\mathrm{R})-\mathrm{PK} 11195$ and $\left[{ }^{11} \mathrm{C}\right] \mathrm{PBR} 28$, two radioligands for translocator protein (18 kDa) in human and monkey: implications for positron emission tomographic imaging of this inflammation biomarker. Neuroimage. 2010;49:2924-32.

16. Hagens MHJ, Golla SV, Wijburg MT, Yaqub M, Heijtel D, Steenwijk MD, et al. In vivo assessment of neuroinflammation in progressive multiple sclerosis: a proof of concept study with [ ${ }^{18}$ F]DPA714 PET. J Neuroinflammation. 2018; 15:314.

17. Herranz E, Gianni C, Louapre C, Treaba CA, Govindarajan ST, Ouellette R, et al. Neuroinflammatory component of gray matter pathology in multiple sclerosis. Ann Neurol. 2016;80:776-90.

18. Oh U, Fujita M, Ikonomidou VN, Evangelou IE, Matsuura E, Harberts E, et al. Translocator protein PET imaging for glial activation in multiple sclerosis. J Neurolmmune Pharmacol. 2011;6:354-61.

19. Chaney A, Cropper HC, Johnson EM, Lechtenberg KJ, Peterson TC, Stevens MY, et al. ${ }^{11} \mathrm{C}-\mathrm{DPA}-713$ versus ${ }^{18} \mathrm{~F}-\mathrm{GE}-180$ : a preclinical comparison of translocator protein $18 \mathrm{kDa}$ PET tracers to visualize acute and chronic neuroinflammation in a mouse model of ischemic stroke. J Nucl Med. 2019; 60:122-8.

20. Coughlin JM, Yang T, Rebman AW, Bechtold KT, Du Y, Mathews WB, et al. Imaging glial activation in patients with post-treatment Lyme disease symptoms: a pilot study using $\left[{ }^{11} \mathrm{C}\right] \mathrm{DPA}-713$ PET. J Neuroinflammation. 2018;15:346

21. Hamelin L, Lagarde J, Dorothée G, Potier MC, Corlier F, Kuhnast B, et al. Distinct dynamic profiles of microglial activation are associated with progression of Alzheimer's disease. Brain. 2018;141:1855-70.

22. Coughlin JM, Wang Y, Munro CA, Ma S, Yue C, Chen S, et al. Neuroinflammation and brain atrophy in former NFL players: an in vivo multimodal imaging pilot study. Neurobiol Dis. 2015;74:58-65.

23. Kumar A, Muzik O, Shandal V, Chugani D, Chakraborty P, Chugani HT. Evaluation of age-related changes in translocator protein (TSPO) in human brain using ${ }^{11} \mathrm{C}$-[R]-PK11195 PET. J Neuroinflammation. 2012;9:232.

24. Lyoo CH, Ikawa M, Liow JS, Zoghbi SS, Morse CL, Pike WW, et al. Cerebellum can serve as a pseudo-reference region in Alzheimer disease to detect neuroinflammation measured with PET radioligand binding to translocator protein. J Nucl Med. 2015;56:701-6.

25. Owen DR, Yeo AJ, Gunn RN, Song K, Wadsworth G, Lewis A, et al. An 18kDa translocator protein (TSPO) polymorphism explains differences in binding affinity of the PET radioligand PBR28. J Cereb Blood Flow Metab. 2012;32:1-5

26. Guo Q, Owen DR, Rabiner EA, Turkheimer FE, Gunn RN. Identifying improved TSPO PET imaging probes through biomathematics: the impact of multiple TSPO binding sites in vivo. Neuroimage. 2012;60:902-10.

27. Widdess-Walsh P, Diehl B, Najm I. Neuroimaging of focal cortical dysplasia. J Neuroimaging. 2006:16:185-96.

28. Guerrini R, Duchowny M, Jayakar P, Krsek P, Kahane P, Tassi L, et al. Diagnostic methods and treatment options for focal cortical dysplasia. Epilepsia. 2015;56:1669-86.

29. Banati RB, Goerres GW, Myers R, Gunn RN, Turkheimer FE, Kreutzberg GW, et al. [ $\left.{ }^{11} \mathrm{C}\right](\mathrm{R})-\mathrm{PK} 11195$ positron emission tomography imaging of activated microglia in vivo in Rasmussen's encephalitis. Neurology. 1999;53:2199-203.

30. Goerres GWRT, Duncan J, Banati RB. Imaging cerebral vasculitis in refractory epilepsy using $\left[{ }^{11} \mathrm{C}\right](\mathrm{R})$-PK11195 positron emission tomography. AJR Am J Roentgenol. 2001;176:1016-8.

31. Kumar A, Chugani HT, Luat A, Asano E, Sood S. Epilepsy surgery in a case of encephalitis: use of ${ }^{11} \mathrm{C}-\mathrm{PK} 11195$ positron emission tomography. Pediatr Neurol. 2008;38:439-42.

32. Gershen LD, Zanotti-Fregonara P, Dustin IH, Liow JS, Hirvonen J, KreisI WC, et al. Neuroinflammation in temporal lobe epilepsy measured using positron emission tomographic imaging of translocator protein. JAMA Neurol. 2015;72:882-8

33. Bascunana $P$, Gendron $T$, Sander $K$, Jahreis I, Polyak A, Ross TL, et al. Ex vivo characterization of neuroinflammatory and neuroreceptor changes during 
epileptogenesis using candidate positron emission tomography biomarkers. Epilepsia. 2019;60:2325-33.

34. Brackhan M, Bascunana P, Ross TL, Bengel FM, Bankstahl JP, Bankstahl M. $\left[^{18}\right.$ F]GE180 positron emission tomographic imaging indicates a potential double-hit insult in the intrahippocampal kainate mouse model of temporal lobe epilepsy. Epilepsia. 2018;59:617-26.

35. Butler T, Li Y, Tsui W, Friedman D, Maoz A, Wang X, et al. Transient and chronic seizure-induced inflammation in human focal epilepsy. Epilepsia. 2016:57:e191-4.

36. Andoh M, Ikegaya Y, Koyama R. Synaptic pruning by microglia in epilepsy. J Clin Med. 2019:8:2170.

37. Szalay G, Martinecz B, Lenart N, Kornyei Z, Orsolits B, Judak L, et al. Microglia protect against brain injury and their selective elimination dysregulates neuronal network activity after stroke. Nat Commun. 2016;7:11499.

38. Webster KM, Sun M, Crack P, O'Brien TJ, Shultz SR, Semple BD. Inflammation in epileptogenesis after traumatic brain injury. J Neuroinflammation. 2017; 14:10.

39. Kalk NJ, Owen DR, Tyacke RJ, Reynolds R, Rabiner EA, Lingford-Hughes AR, et al. Are prescribed benzodiazepines likely to affect the availability of the $18 \mathrm{kDa}$ translocator protein (TSPO) in PET studies? Synapse. 2013;67:909-12.

40. Lauro C, Limatola C. Metabolic reprograming of microglia in the regulation of the innate inflammatory response. Front Immunol. 2020;11:493.

41. Burneo JG, Poon R, Kellett S, Snead OC. The utility of positron emission tomography in epilepsy. Can J Neurol Sci. 2015;42(6):360-71.

42. O'Brien TJ, Newton MR, Cook MJ, Berlangieri SU, Kilpatrick C, Morris K, et al. Hippocampal atrophy is not a major determinant of regional hypometabolism in temporal lobe epilepsy. Epilepsia. 1997;38:74-80.

43. Boison D, Steinhäuser C. Epilepsy and astrocyte energy metabolism. Glia. 2018;66(6):1235-43.

44. Schur S, Allen V, White A, Mirsky D, Stence N, O'Neill B, et al. Significance of FDG-PET Hypermetabolism in children with intractable focal epilepsy. Pediatr Neurosurg. 2018;53(3):153-62.

45. Brackhan M, Bascunana P, Postema JM, Ross TL, Bengel FM, Bankstahl M, et al. Serial quantitative TSPO-targeted PET reveals peak microglial activation up to 2 weeks after an epileptogenic brain insult. J Nucl Med. 2016;57: $1302-8$.

46. Nguyen DL, Wimberley C, Truillet C, Jego B, Caille F, Pottier G, et al. Longitudinal positron emission tomography imaging of glial cell activation in a mouse model of mesial temporal lobe epilepsy: toward identification of optimal treatment windows. Epilepsia. 2018;59:1234-44.

47. Sanz P, Garcia-Gimeno MA. Reactive glia inflammatory signaling pathways and epilepsy. Int J Mol Sci. 2020;21:4096.

48. Dickstein LP, Liow JS, Austermuehle A, Zoghbi S, Inati SK, Zaghloul K, et al. Neuroinflammation in neocortical epilepsy measured by PET imaging of translocator protein. Epilepsia. 2019;60:1248-54.

49. Venneti S, Lopresti BJ, Wiley CA. The peripheral benzodiazepine receptor (Translocator protein $18 \mathrm{kDa}$ ) in microglia: from pathology to imaging. Prog Neurobiol. 2006;80:308-22.

50. Landau WM, Kleffner FR. Syndrome of acquired aphasia with convulsive disorder in children. Neurology. 1957;7:523-30.

51. Ernst M, Freed ME, Zametkin AJ. Health hazards of radiation exposure in the context of brain imaging research: special consideration for children. J Nucl Med. 1998;39:689-98.

52. Ron E, Modan B, Preston D, Alfandary E, Stovall M, Boice JD Jr. Thyroid neoplasia following low-dose radiation in childhood. Radiat Res. 1989;120: 516-31.

53. Billen D. Spontaneous DNA damage and its significance for the "negligible dose" controversy in radiation protection. Radiat Res. 1990;124:242-5.

54. Endres CJ, Pomper MG, James M, Uzuner O, Hammoud DA, Watkins CC, et al. Initial evaluation of 11C-DPA-713, a novel TSPO PET ligand, in humans. Nucl Med. 2009:50(8):1276-82.

55. Gerhard A, Schwarz J, Myers R, Wise R, Banati RB. Evolution of microglial activation in patients after ischemic stroke: a [11C](R)-PK11195 PET study. Neuroimage. 2005;24(2):591-5.

\section{Publisher's Note}

Springer Nature remains neutral with regard to jurisdictional claims in published maps and institutional affiliations.

\section{Ready to submit your research? Choose BMC and benefit from:}

- fast, convenient online submission

- thorough peer review by experienced researchers in your field

- rapid publication on acceptance

- support for research data, including large and complex data types

- gold Open Access which fosters wider collaboration and increased citations

- maximum visibility for your research: over $100 \mathrm{M}$ website views per year

At BMC, research is always in progress.

Learn more biomedcentral.com/submissions 